\title{
Characterization of phenotypes and predominant skeletodental patterns in pre-adolescent patients with Pierre-Robin sequence
}

\author{
ll-Hyung Yang ${ }^{a}$ (1) \\ Jee Hyeok Chung ${ }^{b}$ \\ Hyeok Joon Lee ${ }^{\mathrm{a}}$ \\ ll-Sik Cho ${ }^{\mathrm{c}}$ \\ Jin-Young $\mathrm{Choi}^{\mathrm{d}}$ \\ Jong-Ho Lee ${ }^{\mathrm{d}}$ \\ Sukwha Kim ${ }^{\mathrm{e}}$ \\ Seung-Hak Baek ${ }^{\mathrm{a}}$ (1)
}

${ }^{a}$ Department of Orthodontics, School of Dentistry and Dental Research Institute, Seoul National University, Seoul, Korea

${ }^{\mathrm{b}}$ Department of Plastic and Reconstructive Surgery, Seoul National University Children's Hospital, Seoul, Korea

'Private Practice, Pohang, Korea

${ }^{\mathrm{d}}$ Departement of Oral and Maxillofacial Surgery, School of Dentistry and Dental Research Institute, Seoul National University, Seoul, Korea 'Department of Plastic and Reconstructive Surgery, College of Medicine, Seoul National University, Seoul, Korea

\begin{abstract}
Objective: To investigate the phenotypes and predominant skeletodental pattern in pre-adolescent patients with Pierre-Robin sequence (PRS). Methods: The samples consisted of 26 Korean pre-adolescent PRS patients ( 11 boys and 15 girls; mean age at the investigation, 9.20 years) treated at the Department of Orthodontics, Seoul National University Dental Hospital between 1998 and 2019. Dental phenotypes, oral manifestation, cephalometric variables, and associated anomalies were investigated and statistically analyzed. Results: Congenitally missing teeth (CMT) were found in 34.6\% of the patients (n $=9 / 26,20$ teeth, 2.22 teeth per patient $)$ with 55.5\% $(n=5 / 9)$ exhibiting bilaterally symmetric missing pattern. The mandibular incisors were the most common CMT $(n=11 / 20)$. Predominant skeletodental patterns included Class 11 relationship (57.7\%), posteriorly positioned maxilla (76.9\%) and mandible (92.3\%), hyper-divergent pattern (92.3\%), high gonial angle (65.4\%), small mandibular body length to anterior cranial base ratio (65.4\%), linguoversion of the maxillary incisors (76.9\%), and linguoversion of the mandibular incisors $(80.8 \%)$. Incomplete cleft palate (CP) of hard palate with complete CP of soft palate $(61.5 \%)$ was the most frequently observed, followed by complete $\mathrm{CP}$ of hard and soft palate $(19.2 \%)$ and CP of soft palate $(19.2 \%)(p<0.05)$. However, CP severity did not show a significant correlation with any cephalometric variables except incisor mandibular plane angle $(p<0.05)$. Five craniofacial and 15 extra-craniofacial anomalies were observed (53.8\% patients); this implicated the need of routine screening. Conclusions: The results might provide primary data for individualized diagnosis and treatment planning for pre-adolescent PRS patients despite a single institution-based data.
\end{abstract}

[Korean J Orthod 2021;51(5):337-345]

Key words: Pierre-Robin sequence, Phenotype, Skeletodental pattern

Received November 23, 2020; Accepted January 7, 2021.

Corresponding author: Seung-Hak Baek.

Professor, Department of Orthodontics, School of Dentistry and Dental Research Institute, Seoul National University, 101, Daehak-ro, Jongno-gu, Seoul 03080, Korea.

Tel +82-2-2072-3952 e-mail drwhite@unitel.co.kr

How to cite this article: Yang $\mathrm{lH}$, Chung JH, Lee HJ, Cho IS, Choi JY, Lee JH, Kim S, Baek SH. Characterization of phenotypes and predominant skeletodental patterns in preadolescent patients with Pierre-Robin sequence. Korean J Orthod 2021;51:337-345.

(C) 2021 The Korean Association of Orthodontists.

This is an Open Access article distributed under the terms of the Creative Commons Attribution Non-Commercial License (http://creativecommons.org/licenses/by-nc/4.0) which permits unrestricted non-commercial use, distribution, and reproduction in any medium, provided the original work is properly cited. 


\section{INTRODUCTION}

The main features of Pierre-Robin sequence (PRS) are micrognathia, glossoptosis, respiratory difficulties, and/ or cleft palate (CP). ${ }^{1}$ Possible etiologies for a micrognathic mandible in these patients include intrauterine compression of the fetal mandible and de-novo mutations of GAD1, PVRL1, SOX9 or KCNJ2 gene. ${ }^{2}$

The incidence of PRS is known to be between 1/2,685 and $1 / 30,000 ;^{3-5}$ this wide range can be attributed to differences in ethnic background and geographic regions as well as the absence of a consensus regarding uniform diagnostic criteria. Most clinical studies on PRS have usually focused on the management of respiratory probelms, ${ }^{6-8}$ size and shape of the mandible, ${ }^{9,10}$ and presence of mandibular catch-up growth. ${ }^{11-15}$

Since micrognathia is a key factor in occurrence of PRS, the skeletodental pattern including the position, shape, and size of the maxillomandibular complex and the inclination of the maxillary and mandibular incisors should be considered at the time of diagnosis by orthodontists.

With regard to dental anomalies in PRS patients, several studies have reported a high prevalence of congenitally missing tooth and taurodontism. ${ }^{16-18}$ However, the prevalence of other dental anomalies including microdontia, short root, and supernumerary tooth in Korean PRS patients remains to be investigated. Furthermore, to the best of our knowledge, no clinical demographic studies have evaluated the oral manifestations, detailed skeletodental pattern of the maxillomandibular complex, and associated anomalies in Korean pre-adolescent patients with PRS. Therefore, the purpose of this retrospective study was to investigate the dental phenotypes, oral manifestations, predominant skeletodental pattern of the maxillomandibular complex, and associated anomalies in Korean pre-adolescent patients with PRS.

\section{MATERIALS AND METHODS}

The study design of this study was a retrospective one. The initial samples were PRS patients who visited the
Department of Orthodontics, Seoul National University Dental Hospital (SNUDH), Seoul, Korea. The inclusion criteria were as follows: (1) Korean patients; (2) patients diagnosed with PRS, (3) patients treated by a single orthodontist (BSH); (4) patients treated and/or followedup between 1998 and 2019, (5) patients whose charts, clinical photographs, cephalometric and panoramic radiographs were available; and (6) patients whose chronological age was between 5 and 12 years at the time of investigation of oral manifestations, dental phenotypes, and skeletodental pattern of the maxillomandibular complex. Patients who were receiving orthodontic or orthopedic treatment at the time of cephalometric analysis and dental phenotype investigation were excluded in order to avoid any influence on the skeletodental pattern of the maxillomandibular complex. This study was reviewed and approved by the Institutional Review Board of the SNUDH (ERI20010).

As a result, the final samples consisted of 26 unrelated Korean pre-adolescent patients with PRS (11 boys and 15 girls). The mean age at the first consultation at the Department of Orthodontics, SNUDH (T0 stage) was 7.63 \pm 2.49 years, while that at the time of cephalometric analysis and dental phenotype investigation ( $\mathrm{T} 1$ stage) was $9.20 \pm 1.46$ years.

The prevalence of dental phenotype (congenitally missing tooth, microdontia, tooth with short root, tooth with taurodontism, and supernumerary tooth), oral manifestations (severity of CP and degree of overbite), cephalometric variables (sella-nasion-A point angle [SNA], sella-nasion-B point angle [SNB], A point-nasion$B$ point angle [ANB], sella-nasion to mandibular plane angle [SN-MP], mandibular body length to anterior cranial base ratio \{gonion-menton [Go-Me]/sella-nasion $[\mathrm{S}-\mathrm{N}]\}$, gonial angle, upper incisor to sella-nasion angle [U1-SN], and incisor mandibular plane angle [IMPA]) at the T1 stage were investigated along with associated anomalies. Korean ethnic norms were used to determine the predominant skeletodental pattern of the maxillomandibular complex with reference to the cephalometric analysis chart used in the Department of Orthodontics, SNUDH and the findings of a previous study. ${ }^{19}$

Table 1. Prevalence of dental phenotypes in Korean pre-adolescent patients with Pierre-Robin sequence

\begin{tabular}{lccc}
\hline \multicolumn{1}{c}{ Dental phenotype } & $\begin{array}{c}\text { Number of patients (\%) } \\
(\mathbf{n}=\mathbf{2 6})\end{array}$ & $\begin{array}{c}\text { Number of tooth } \\
\text { Congenitally missing tooth }\end{array} \quad 9(34.6)$ & $\begin{array}{c}\text { Mean number of tooth } \\
\text { per patient }\end{array}$ \\
\hline Microdontia & $3(11.5)$ & 5 & 2.22 \\
Tooth with short root & $0(0)$ & 0 & 1.67 \\
Tooth with taurodontism & $0(0)$ & 0 & 0 \\
Supernumerary tooth & $1(3.8)$ & 1 & 0 \\
\hline
\end{tabular}

The mean age of patients at the time of dental phenotype investigation (T1 stage) was $9.20 \pm 1.46$ years. 
Yang et al • Skeletodental patterns in Pierre-Robin sequence

Table 2. Summary of the patterns of congenitally missing tooth in Korean pre-adolescent patients with Pierre-Robin sequence

\begin{tabular}{|c|c|c|c|c|c|c|}
\hline \multirow{2}{*}{$\begin{array}{l}\text { Patient } \\
\text { number }\end{array}$} & \multirow[b]{2}{*}{ Sex } & \multirow{2}{*}{$\begin{array}{l}\text { Number of } \\
\text { congenitally } \\
\text { missing tooth }\end{array}$} & \multicolumn{3}{|c|}{ Location of the congenitally missing tooth } & \multirow{2}{*}{$\begin{array}{c}\text { Presence of bilateral } \\
\text { and symmetrical } \\
\text { missing }\end{array}$} \\
\hline & & & $\begin{array}{c}\text { Mandibular } \\
\text { incisor }\end{array}$ & $\begin{array}{c}\text { Mandibular } \\
\text { premolar }\end{array}$ & $\begin{array}{l}\text { Maxillary } \\
\text { premolar }\end{array}$ & \\
\hline$\# 4$ & Male & 3 & $\# 32,42$ & \#45 & & Yes \\
\hline$\# 6$ & Female & 4 & $\# 31,32,41,42$ & & & Yes \\
\hline$\# 8$ & Female & 2 & & \#35 & $\# 15$ & \\
\hline \#15 & Male & 2 & & \#45 & \#15 & \\
\hline$\# 16$ & Female & 2 & & $\# 35,45$ & & Yes \\
\hline$\# 18$ & Male & 1 & & & $\# 15$ & \\
\hline$\# 24$ & Male & 2 & $\# 32,42$ & & & Yes \\
\hline$\# 25$ & Male & 1 & & & $\# 25$ & \\
\hline \#26 & Male & 3 & $\# 31,32,42$ & & & Yes \\
\hline Sum & $\begin{array}{l}6 \text { boys } \\
\text { and } 3 \text { girls }\end{array}$ & 20 & 11 & 5 & 4 & 5 \\
\hline
\end{tabular}

The mean age of patients at the time of dental phenotype investigation (T1 stage) was $9.20 \pm 1.46$ years.

Descriptive statistics, Man-Whitney $U$ test, chi-square goodness of fit test, chi-square independence test, Fisher's exact test, and Spearman's correlation analysis were used for statistical analysis with SPSS software version 12.0 (SPSS Inc., Chicago, IL, USA). A $p$-value of $<0.05$ was considered statistically significant.

\section{RESULTS}

\section{Dental phenotypes (Tables 1 and 2)}

In total, $34.6 \%$ of PRS patients exhibited congenitally missing tooth ( $n=9 / 26,20$ teeth, 2.22 teeth per patient). The most common congenitally missing tooth was the mandibular incisors $(n=11 / 20,55.0 \%)$, followed by the mandibular premolars $(n=5 / 20,25.0 \%)$, and the maxillary premolars $(n=4 / 20,20.0 \%)$. However, none of the patient showed congenital missing of the maxillary incisors. In addition, among nine patients who exhibited congenitally missing tooth, seven patients $(77.8 \%)$ had more than two missing teeth; while five patients (55.5\%) showed a bilateral and symmetric missing pattern.

Microdontia was found in $11.5 \%$ of PRS patients $(\mathrm{n}=$ 3/26, 5 teeth, 1.67 teeth per patient), which was observed at the maxillary lateral incisors. A supernumerary tooth was found only in one PRS patient ( $n=1 / 26,1$ tooth, 1 tooth per patient) at the maxillary incisor area. None of the patients exhibited a tooth with short root or with taurodontism.

\section{Oral manifestations (Table 3)}

In terms of CP severity, incomplete CP of hard palate with complete $\mathrm{CP}$ of soft palate $(-\mathrm{hSh}-, 61.5 \%, \mathrm{n}=$
Table 3. Distribution of cleft palate severity and overbite in Korean pre-adolescent patients with Pierre-Robin sequence (PRS)

\begin{tabular}{clcc}
\hline \multicolumn{2}{c}{ Oral manifestations } & PRS (n= 26) & p-value \\
\hline CP severity $^{\dagger}$ & -S- & $5(19.2)$ & $0.01^{*}$ \\
& -hSh- & $16(61.5)$ & \\
& -HSH- & $5(19.2 \%)$ & \\
Overbite $^{*}$ & Normal overbite & $16(61.5)$ & $0.001^{* *}$ \\
& Deep bite & $9(34.6)$ & \\
& Open bite & $1(3.8)$ & \\
\hline
\end{tabular}

Values are presented as number (\%).

Deep bite was defined as the full coverage of the maxillary incisor over the mandibular incisor. Open bite was defined as absence of vertical overlap between the maxillary and mandibular incisors.

The mean age of patients at the time of oral manifestation investigation ( $\mathrm{T} 1$ stage) was $9.20 \pm 1.46$ years.

CP, cleft palate; -S-, complete CP of soft palate; -hSh-, incomplete $\mathrm{CP}$ of hard palate and complete $\mathrm{CP}$ of soft palate; -HSH-, complete CP of hard and soft palate.

${ }^{*} p<0.05,{ }^{* *} p<0.01$.

${ }^{\dagger}$ Chi-square goodness of fit test was performed.

${ }^{\ddagger}$ Fisher's exact test was performed.

$16 / 26$ ) was the most commonly observed, followed by CP of soft palate (-S-, 19.2\%, $n=5 / 26)$ and complete CP of hard and soft palate (-HSH-, 19.2\%, $n=5 / 26$ ) $(p<0.05)$.

In terms of overbite, the frequency of open bite (3.8\%, $n=1 / 26)$ was lower than that of normal overbite (61.5\%, $\mathrm{n}=16 / 26)$ and deep bite $(34.6 \%, \mathrm{n}=9 / 26)(p<0.01)$. 


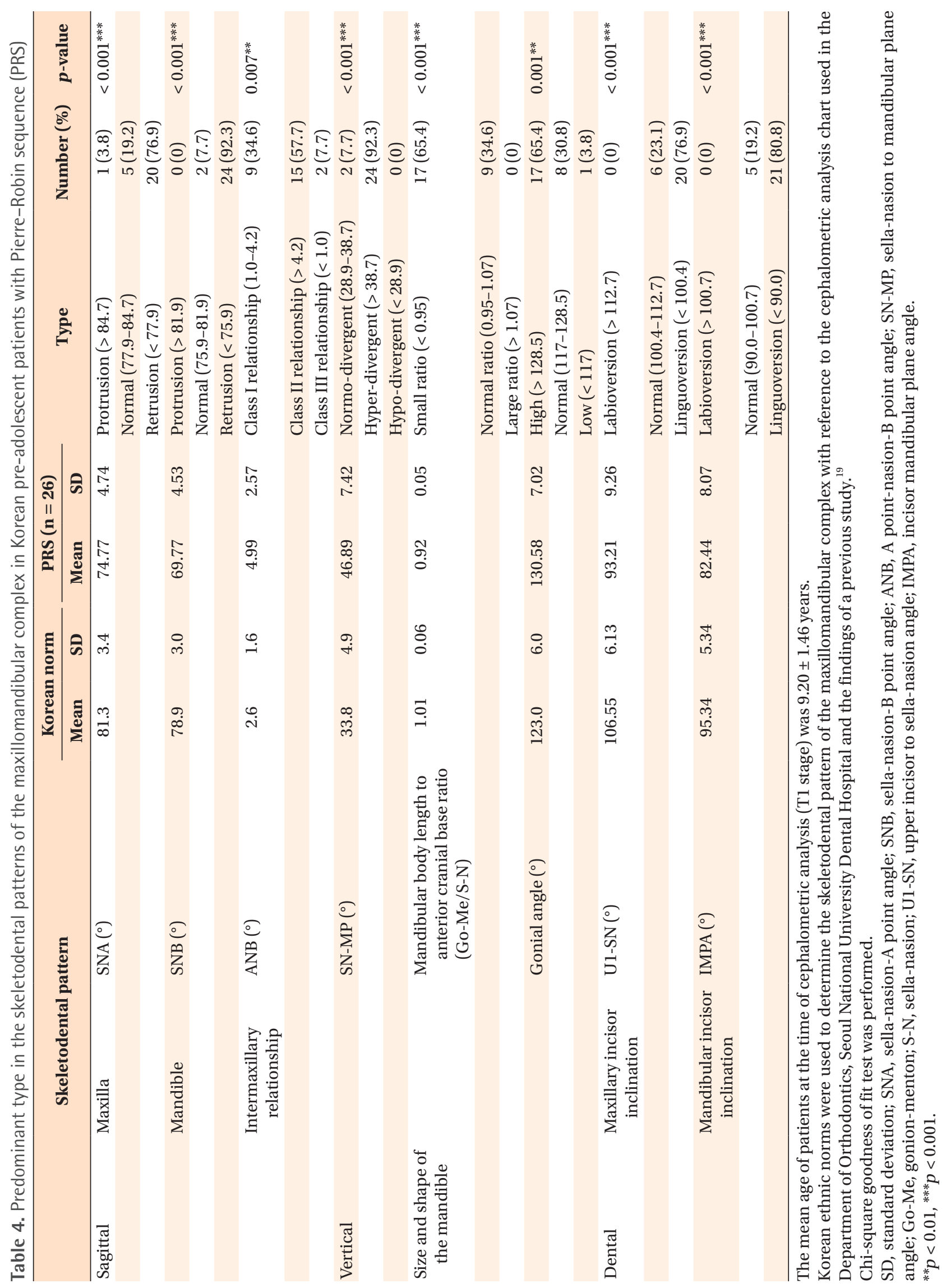


Table 5. Correlations of skeletodental pattern with mandibular body length (Go-Me) and cleft palate severity in Korean pre-adolescent patients with Pierre-Robin sequence

\begin{tabular}{|c|c|c|c|c|}
\hline \multirow{2}{*}{ Cephalometric variable } & \multicolumn{2}{|c|}{ Mandibular body length } & \multicolumn{2}{|c|}{ Severity of cleft palate } \\
\hline & $\rho$-value ${ }^{\dagger}$ & $p$-value & $\rho$-value ${ }^{\dagger}$ & $p$-value \\
\hline SNA & -0.014 & 0.947 & -0.281 & 0.164 \\
\hline SNB & 0.230 & 0.258 & -0.265 & 0.191 \\
\hline ANB & -0.462 & $0.018^{*}$ & -0.099 & 0.630 \\
\hline SN-MP & -0.504 & $0.009 * *$ & 0.223 & 0.273 \\
\hline Gonial angle & -0.477 & $0.014^{*}$ & 0.256 & 0.206 \\
\hline Ramus height & 0.612 & $0.001^{* *}$ & -0.306 & 0.128 \\
\hline Mandibular body length (Go-Me) & - & - & -0.161 & 0.431 \\
\hline Mandibular body length to anterior cranial base ratio (Go-Me/S-N) & 0.567 & $0.003^{* *}$ & 0.292 & 0.148 \\
\hline U1-SN & -0.066 & 0.750 & 0.074 & 0.718 \\
\hline IMPA & 0.404 & $0.041^{*}$ & -0.409 & $0.038^{*}$ \\
\hline
\end{tabular}

The mean age of patients at the time of cephalometric analysis (T1 stage) was $9.20 \pm 1.46$ years.

Spearman correlation analysis was performed.

${ }^{*} p<0.05,{ }^{* *} p<0.01$.

${ }^{\dagger}$ Pearson product-moment correlation coefficient.

See Table 4 for definitions of each landmark or measurement.

\section{The mean values of cephalometric variables (Table 4)}

PRS patients had Class 11 relationship (ANB, 5.0 $0^{\circ}$, posteriorly positioned maxilla (SNA, $74.8^{\circ}$ ), posteriorly positioned mandible (SNB, $69.8^{\circ}$ ), hyper-divergent pattern (SN-MP, $\left.46.9^{\circ}\right)$, high gonial angle $\left(130.6^{\circ}\right)$, small mandibular body length to anterior cranial base length ratio (Go-Me/S-N, 0.92), linguoversion of the maxillary incisor ( $\mathrm{U} 1-\mathrm{SN}, 93.2^{\circ}$ ), and linguoversion of the mandibular incisor (IMPA, 82.4 ${ }^{\circ}$ ).

\section{Predominant skeletodental pattern of the maxillomandibular complex (Table 4)}

PRS patients exhibited a higher percentage of the posteriorly positioned maxilla and mandible than normally or forward positioned maxilla and mandible (SNA, $76.9 \%$ vs. $19.2 \%, 3.8 \%, p<0.001$; SNB, $92.3 \%$ vs. $7.7 \%$, $0 \%, p<0.001$ ). Class 11 relationship was more frequently found than Class 1 and Class 111 relationships (ANB, $57.7 \%$ vs. $34.6 \%, 7.7 \%, p<0.01)$. A hyperdivergent pattern was more common than normo-divergent and hypo-divergent patterns (SN-MP, 92.3\% vs. 7.7\%, 0\%, $p<0.001$ ).

In terms of the shape and size of the mandible, high gonial angle was more frequently found than normal and low gonial angles $(65.4 \%$ vs. $30.8 \%, 3.8 \%, p<0.01)$ due to clockwise-rotated morphology of the mandible. Small Go-Me/S-N ratio was more prevalent than normal and large Go-Me/S-N ratios (65.4\% vs. 34.6\%, 0\%, $p<$ $0.001)$.

In terms of the inclination of the maxillary and mandibular incisor, linguoversion was more prevalent than
Table 6. Number and percentage of Korean preadolescent Pierre-Robin sequence patients with and without craniofacial and extra-craniofacial anomalies

\begin{tabular}{lcc}
\hline Variable & Number (\%) & p-value \\
\hline $\begin{array}{l}\text { Patients who had craniofacial and } \\
\text { extra-craniofacial anomalies }\end{array}$ & $14(53.8)$ & \\
$\begin{array}{l}\text { Patients who did not have } \\
\text { craniofacial and extra- }\end{array}$ & $12(46.2)$ & 0.695 \\
craniofacial anomalies & & \\
Sum & 26 & \\
\hline
\end{tabular}

The chi-square goodness of fit test was performed.

normal inclination and labioversion (U1-SN, 76.9\% vs. $23.1 \%$, 0\%; IMPA, $80.8 \%$ vs. $19.2 \%$, $0 \%$; all $p<0.001$ ).

Interestingly, none of the patients showed a forwardpositioned mandible, a hypo-divergent type, a large Go-Me/S-N ratio, and labioversion of the maxillary and mandibular incisors (Table 4).

Correlations between mandibular body length (Go-Me) and skeletodental pattern and between $\mathrm{CP}$ severity and skeletodental pattern (Table 5)

A short mandibular body length (Go-Me) was significantly correlated with Class 11 relationship (ANB, $p<$ $0.05)$, high gonial angle $(p<0.05)$, linguoversion of the mandibular incisor (IMPA, $p<0.05$ ), small Go-Me/S-N ratio $(p<0.01)$, and hyper-divergent pattern $(\mathrm{SN}-\mathrm{MP}$, $p<0.01$ ) (Table 5). However, CP severity did not show a significant correlation with any cephalometric variables 
Table 7. Summary of the craniofacial and extra-craniofacial anomalies observed in Korean pre-adolescent patients with Pierre-Robin sequence

\begin{tabular}{|c|c|c|c|c|c|}
\hline $\begin{array}{l}\text { Associated } \\
\text { anomaly }\end{array}$ & Patient & Sex & Number of anomalies & Extra-craniofacial anomalies & Craniofacial anomalies \\
\hline \multirow[t]{12}{*}{ Absent } & 3 & Female & 0 & & \\
\hline & 5 & Male & 0 & & \\
\hline & 6 & Female & 0 & & \\
\hline & 7 & Male & 0 & & \\
\hline & 12 & Male & 0 & & \\
\hline & 13 & Female & 0 & & \\
\hline & 17 & Female & 0 & & \\
\hline & 19 & Female & 0 & & \\
\hline & 20 & Female & 0 & & \\
\hline & 21 & Female & 0 & & \\
\hline & 22 & Female & 0 & & \\
\hline & 23 & Female & 0 & & \\
\hline \multirow[t]{14}{*}{ Present } & 1 & Female & 1 & Velocardiofacial syndrome & \\
\hline & 2 & Female & 1 & Neurofibromatosis (upper trunk) & \\
\hline & 8 & Female & 1 & Acampomelic campomelic dysplasia & \\
\hline & 9 & Female & 1 & & Tongue tie \\
\hline & 10 & Male & 1 & & Tongue tie \\
\hline & 15 & Male & 1 & Gordon syndrome & \\
\hline & 16 & Female & 1 & Pulmonary veno-occlusive disease & \\
\hline & 11 & Female & 2 & & $\begin{array}{l}\text { Tongue-tie, HFM } \\
\text { with Preauricular skin tag }\end{array}$ \\
\hline & 14 & Male & 2 & Cataract & $\begin{array}{l}\text { Strawberry hemangioma in } \\
\text { the scalp }\end{array}$ \\
\hline & 18 & Male & 2 & Retinal detachment & Subglottic stenosis \\
\hline & 24 & Male & 2 & Coartation of aorta, clinodactyly & \\
\hline & 25 & Male & 2 & $\begin{array}{l}\text { Congenital clubfoot, } \\
\text { congenital clasped thumb }\end{array}$ & \\
\hline & 4 & Male & 3 & $\begin{array}{l}\text { Congenital syndactyly, } \\
\text { cryptorchidism, }\end{array}$ & Nager syndrome \\
\hline & 26 & Male & 3 & Scoliosis, hemivertebrae & $\begin{array}{l}\text { HFM with } \\
\text { Preauricular skin tag }\end{array}$ \\
\hline $\begin{array}{l}14 \text { association } \\
\text { and } 12 \text { no } \\
\text { association }\end{array}$ & Sum & $\begin{array}{l}11 \text { boys } \\
\text { and } \\
15 \text { girls }\end{array}$ & $\begin{array}{c}7 \text { one anomaly, } \\
5 \text { two anomalies and } \\
2 \text { three anomalies }\end{array}$ & 11 patients with 15 kinds & 6 patients with 5 kinds \\
\hline
\end{tabular}

HFM, hemifacial microsomia.

except IMPA $(p<0.05)$.

\section{Associated anomalies (Tables 6 and 7)}

Craniofacial and/or extra-craniofacial anomalies were observed in 53.8\% of PRS patients. However, there was no difference between the percentages of patients with anomalies and that of patients without anomalies (53.8\% vs. $46.2 \%, p>0.05$ ).
In terms of the number of associated anomalies, one anomaly was most common $(n=7 / 14,50.0 \%)$, followed by two anomalies $(n=5 / 14,35.7 \%)$ and three anomalies $(\mathrm{n}=2 / 14,14.3 \%)$. Five kinds of craniofacial anomalies were found in $42.9 \%$ of patients $(n=6 / 14$; Nager syndrome, tongue tie, hemifacial microsomia, strawberry hemangioma, and subglottic stenosis). Meanwhile, 15 kinds of extra-craniofacial anomalies were found in 
$78.6 \%$ of patients $(n=11 / 14$; cardiovascular anomaly [ $\mathrm{n}$ $=3]$, digit anomaly $[n=3]$, eye anomaly [ $n=2]$, long bone anomaly $[n=1]$, skin anomaly $[n=1]$, genital anomaly [ $n=1]$, kidney anomalies [ $n=1]$, and vertebral anomaly $[n=1])$. Three patients $(21.4 \%)$ had both craniofacial and extra-craniofacial anomalies.

\section{DISCUSSION}

\section{Dental phenotypes}

In the present study, congenitally missing tooth was observed in $34.6 \%$ of PRS patients (Table 1), which was relatively lower than Antonarakis et al. ${ }^{16}$ (42\%) and de Smalen et al. ${ }^{17}(47.8 \%)$ but higher than Mateo-Castillo et al. ${ }^{18}(22.7 \%)$.

de Smalen et al. ${ }^{17}$ reported that the most frequently missing teeth were the mandibular second premolars and maxillary lateral incisors. However, the present study showed different results. First, the most prevalent congenitally missing tooth was the mandibular incisor, followed by the mandibular premolar and maxillary premo$\operatorname{lar}$ (55.0\%, 25.0\%, 20.0\%; Table 2). Second, none of the patients showed congenital missing of the maxillary incisor (Table 2). Since the mean age at the time of dental phenotype investigation (T1 stage) was 9.20 years in the present study, congenital missing of the maxillary incisor and any other teeth could be properly determined. Therefore, different results might could be attributed to differences in the ethnic background and geographic regions as well as the age of patients between de Smalen et al.' study ${ }^{17}$ and this study (more than 7 years vs. 9.20 years).

Antonarakis et al., ${ }^{16}$ in their systematic review and meta-analysis of nonsyndromic PRS, reported that the mandibular second premolars (\#35 and \#45, 26\%) were the most common teeth to show a bilateral and symmetric pattern of congenital missing, followed by the maxillary second premolars (\#15 and \#25, 14\%). However, in the present study, the mandibular incisor was the most common tooth showing a bilateral and symmetric pattern of congenitally missing, followed by the mandibular second premolar $(80 \%, n=4 / 5 ; 20 \%, n=$ $1 / 5$; Table 2). The reason might be due to differences in the ethnic background and geographic regions.

Mateo-Castillo et al., ${ }^{18}$ in their retrospective study, reported that taurodontism was the most prevalent dental phenotype (92.7\% in nonsyndromic PRS patients). However, in the present study, taurodontism was not found (Table 1).

\section{Oral manifestations (Table 3)}

In the present study, the distribution of CP severity significantly differed in PRS patients (complete CP of soft palate [-S-, 19.2\%]; incomplete CP of hard palate with complete CP of soft palate [-hSh-, 61.5\%], and complete CP of hard and soft palate [-HSH-, 19.2\%], $p$ $<0.05$, Table 3$)$. Since micrognathia leads to glossoptosis and/or failure of the palatal fusion process, the sagittal length and transverse width of CP might be indirectly related with the size of the mandible. ${ }^{6,13}$ Further study is necessary to investigate this topic.

In the present study, PRS patients exhibited normal overbite and deep bite (61.5\% and 34.6\%, Table 3) despite hyper-divergent pattern and high gonial angle (mean SN-MP, $46.9^{\circ}$; mean gonial angle, $130.6^{\circ}$; Table 4). These might be related with linguoversion of the maxillary and mandibular incisors (mean U1-SN, 93.2 ; mean IMPA, $82.4^{\circ}$; Table 4).

\section{Cephalometric analysis of the skeletodental pattern (Table 4)}

In the present study, PRS patients exhibited Class 11 relationship, posteriorly positioned maxilla and mandible, hyper-divergent pattern, high gonial angle, and linguoversion of the maxillary and mandibular incisors (mean values: ANB, 5.0 ; SNA, 74.8 ${ }^{\circ}$; SNB, 69.8 ; SNMP, $46.9^{\circ}$; gonial angle, $130.6^{\circ}$; U1-SN, $93.2^{\circ}$; IMPA, $82.4^{\circ}$; Table 4$)$. These findings were similar to the results from previous studies. ${ }^{9,12,14,20}$

The finding that PRS patients had small mandibular body length to anterior cranial base length ratio (GoMe/S-N, 0.92; Table 4) indicates that PRS patients have a short mandibular body length despite relatively normal length of the anterior cranial base.

\section{Predominant skeletodental pattern of the maxillomandibular complex}

In terms of the position of the maxilla and mandible, the posteriorly positioned maxilla and mandible was a predominant phenotype in the present study (SNA, 76.9\%; SNB, 92.3\%; all $p<0.001$, Table 4). This might be due to the combined effects of post-surgical scar tissue in the palate on maxillary growth and micrognathia of the mandible itself. Furthermore, Class 11 relationship was predominant (ANB, 57.7\%, $p<0.01$; Table 4) because the mandible is more posteriorly positioned than the maxilla. Hyperdivergent pattern was predominant (SN-MP, 92.3\%, $p<0.001$; Table 4) due to the vertical growth pattern of the maxillomandibular complex.

In terms of the shape and size of the mandible, high gonial angle and small Go-Me/S-N ratio were predominant (gonial angle, 65.4\%, $p<0.01$; Go-Me/S-N ratio, $65.4 \%, p<0.001$; Table 4) due to clockwise-rotated morphology of the mandible and relatively short mandibular body length.

In terms of incisor inclination, linguoversion of the maxillary and mandibular incisors was predominant (U1SN, 76.9\%; IMPA, 80.8\%; all $p<0.001$; Table 4). Lin- 
guoversion of the maxillary incisors might occur due to dental compensation in Class 11 relationship, while linguoversion of the mandibular incisors might occur due to the pressure from the lower lip or the high prevalence of congenital missing of the mandibular incisors (Table 2).

\section{Correlations of skeletodental pattern with mandibular body length (Go-Me) and $\mathrm{CP}$ severity}

In the present study, with a decrease in the mandibular body length (Go-Me), the gonial angle, hyperdivergent pattern, and Class 11 relationship increased in Korean adolescent patients with PRS (gonial angle, $p$ $<0.05$; SN-GoMe, $p<0.01$; ANB, $p<0.05$; Table 5). These findings indicate that PRS patients had a typical size, shape and growth pattern of the mandible (micrognathia, high gonial angle, and clockwise-rotated morphology of the mandible), which can worsen the Class 11 relationship.

Do et al. ${ }^{10}$ reported that a large CP at the time of primary palatorraphy was associated with an increase in the degree of mandibular retrusion (small value of $\mathrm{SNB}, \mathrm{rs}=-0.5, p<0.05)$. However, the present study exhibited that $\mathrm{CP}$ severity did not have a significant correlation with cephalometric variables, including SNB and mandibular body length (Go-Me) (Table 5). The size and shape of the mandible might directly affect the tongue position during development process, and this could influence the palatal fusion process and size of $\mathrm{CP}^{6,13}$ Therefore, it is necessary to investigate the relationships among the degree of micrognathia, position of the tongue, and severity of CP in patients with PRS in future studies.

\section{Associated anomalies}

The finding that more than half of PRS patients $(53.8 \%)$ had craniofacial and/or extra-craniofacial anomalies including velocardiofacial syndrome, acampomelic campomelic dysplasia, pulmonary veno-occlusive disease, Nager syndrome, and Gordon syndrome (Tables 6 and 7) was similar to the results of previous studies.,21-23 Therefore, routine screening should be performed to determine the presence of any associated anomalies or syndromes in neonates with PRS.

Although this study was limited by the retrospective, single-center design and the small sample size, we were able to obtain some meaningful clinical data for Korean preadolescent patients with PRS. Since airway problems in neonates with PRS are an important issue for survival and growth, it is necessary to investigate the type and timing of airway treatment modalities for PRS patients in Korea. In addition, a nationwide multi-center study with a large sample size and systematic statistical analyses should be performed to determine the appropriate orthodontic diagnosis and treatment plan for PRS patients.

\section{CONCLUSION}

- One third of Korean pre-adolescent patients with PRS showed congenitally missing tooth, and half of them exhibited a bilateral and symmetric missing pattern.

- The CP severity was not significantly correlated with any cephalometric variables except IMPA.

- The predominant skeletodental patterns included Class 11 relationship, posteriorly positioned maxilla and mandible, hyper-divergent pattern, high gonial angle, small mandibular body length to anterior cranial base ratio, and linguoversion of the maxillary and mandibular incisors.

- Nearly half of PRS patients had craniofacial and/or extra-craniofacial anomalies, which implicated the need of routine screening.

- Although this study was based on data from a single university hospital, the results from this study might provide primary data for individualized diagnosis and treatment planning for Korean pre-adolescent patients with PRS.

\section{CONFLICTS OF INTEREST}

No potential conflict of interest relevant to this article was reported.

\section{REFERENCES}

1. Cole A, Lynch P, Slator R. A new grading of Pierre Robin sequence. Cleft Palate Craniofac J 2008; 45:603-6.

2. Jakobsen LP, Knudsen MA, Lespinasse J, García Ayuso C, Ramos C, Fryns JP, et al. The genetic basis of the Pierre Robin sequence. Cleft Palate Craniofac J 2006;43:155-9.

3. Bush PG, Williams AJ. Incidence of the Robin Anomalad (Pierre Robin syndrome). Br J Plast Surg 1983;36:434-7.

4. Printzlau A, Andersen M. Pierre Robin sequence in Denmark: a retrospective population-based epidemiological study. Cleft Palate Craniofac J 2004;41:4752.

5. Wright M, Mehendale F, Urquhart DS. Epidemiology of Robin sequence with cleft palate in the East of Scotland between 2004 and 2013. Pediatr Pulmonol 2018;53:1040-5.

6. Godbout A, Leclerc JE, Arteau-Gauthier I, Leclerc LD. Isolated versus Pierre Robin sequence cleft palates: are they different? Cleft Palate Craniofac J 
2014;51:406-11.

7. van Lieshout MJ, Joosten KF, Mathijssen IM, Koudstaal MJ, Hoeve HL, van der Schroeff MP, et al. Robin sequence: a European survey on current practice patterns. J Craniomaxillofac Surg 2015;43:1626-31.

8. Paes EC, Mink van der Molen AB, Muradin MS, Speleman L, Sloot F, Kon M, et al. A systematic review on the outcome of mandibular distraction osteogenesis in infants suffering Robin sequence. Clin Oral lnvestig 2013;17:1807-20.

9. Rogers GF, Lim AA, Mulliken JB, Padwa BL. Effect of a syndromic diagnosis on mandibular size and sagittal position in Robin sequence. J Oral Maxillofac Surg 2009;67:2323-31.

10. Do JBA, Bellerive A, Julien AS, Leclerc JE. Cleft palates and occlusal outcomes in Pierre Robin sequence. Otolaryngol Head Neck Surg 2019;160:24654.

11. Daskalogiannakis J, Ross RB, Tompson BD. The mandibular catch-up growth controversy in Pierre Robin sequence. Am J Orthod Dentofacial Orthop 2001;120:280-5.

12. Hermann NV, Kreiborg S, Darvann TA, Jensen BL, Dahl E, Bolund S. Early craniofacial morphology and growth in children with nonsyndromic Robin Sequence. Cleft Palate Craniofac J 2003;40:131-43.

13. Eriksen J, Hermann NV, Darvann TA, Kreiborg S. Early postnatal development of the mandible in children with isolated cleft palate and children with nonsyndromic Robin sequence. Cleft Palate Craniofac J 2006;43:160-7.

14. Suri S, Ross RB, Tompson BD. Craniofacial morphology and adolescent facial growth in Pierre Robin sequence. Am J Orthod Dentofacial Orthop 2010;137:763-74.

15. Purnell CA, Janes LE, Klosowiak JL, Gosain AK.
Mandibular catch-up growth in Pierre Robin sequence: a systematic review. Cleft Palate Craniofac J 2019;56:168-76.

16. Antonarakis GS, Palaska PK, Suri S. Permanent tooth agenesis in individuals with non-syndromic Robin sequence: a systematic review and meta-analysis. Orthod Craniofac Res 2017;20:216-26.

17. de Smalen A, van Nunen DPF, Hermus RR, Ongkosuwito EM, van Wijk AJ, Griot JPWD, et al. Permanent tooth agenesis in non-syndromic Robin sequence and cleft palate: prevalence and patterns. Clin Oral Investig 2017;21:2273-81.

18. Mateo-Castillo JF, Pagin 0, Marchi Carvalho IM, Olano-Dextre TL, Teixeira das Neves L. Novel dental phenotype in non-syndromic Pierre Robin Sequence: a retrospective study. Arch Oral Biol 2019;97:170-5.

19. Baek SH, Yang WS. A soft tissue analysis on facial esthetics of Korean young adults. Korean J Orthod 1991;21:131-70.

20. Figueroa AA, Glupker TJ, Fitz MG, BeGole EA. Mandible, tongue, and airway in Pierre Robin sequence: a longitudinal cephalometric study. Cleft Palate Craniofac J 1991;28:425-34.

21. Tan TY, Kilpatrick N, Farlie PG. Developmental and genetic perspectives on Pierre Robin sequence. Am J Med Genet C Semin Med Genet 2013;163C:295305.

22. Izumi K, Konczal LL, Mitchell AL, Jones MC. Underlying genetic diagnosis of Pierre Robin sequence: retrospective chart review at two children's hospitals and a systematic literature review. J Pediatr 2012;160:645-50.e2.

23. Karempelis P, Hagen M, Morrell N, Roby BB. Associated syndromes in patients with Pierre Robin sequence. Int J Pediatr Otorhinolaryngol 2020;131: 109842. 